\title{
ESTUDO DO PROCESSO DE SECAGEM DE ARROZ PARBOILIZADO EM LEITO DE JORRO
}

\author{
Estudy of the Drying Process of Parboiled Rice in Spout Bed
}

Estudio del Proceso de Secado de Arroz Parboilizado en Lecho de Chorro

\section{Igor Rodrigues Paolini' ${ }^{1}$, Jônatas Dias Santos ${ }^{2}$, Gilberto A.S Goulart ${ }^{3}$}

${ }^{1}$ Aluno, Universidade Federal de Goiás. Setor de Engenharia de Alimentos, Escola de Agronomia e Engenharia de Alimentos, Universidade Federal de Goiás, Caixa Postal 131, CEP 74.690-900, Goiânia, GO. E-mail: paoliniigorp35@gmail.com

22Aluno, Universidade Federal de Goiás. Setor de Engenharia de Alimentos, Escola de Agronomia e Engenharia de Alimentos, Universidade Federal de Goiás, Caixa Postal 131, CEP 74.690-900, Goiânia, GO. E-mail: jonatasdiasgoiania@ hotmail.com

3Prof. Adjunto, Universidade Federal de Goiás. Setor de Engenharia de Alimentos, Escola de Agronomia e Engenharia de Alimentos, Universidade Federal de Goiás, Caixa Postal 131, CEP 74.001-970, Goiânia, GO. E-mail: gibagoulart@gmail.com

\section{RESUMO}

O arroz é um dos principais produtos de suprimento energético de uma sociedade contemporânea, sendo assim, tornase indispensável estudar processos que venham na perspectiva de obtenção de um produto com propriedades funcionais e organolépticas adequadas ao consumo humano. O presente trabalho teve como objetivo analisar os efeitos das variáveis temperatura e carga de alimentação do secador leito de jorro no processo de secagem do arroz parboilizado, avaliando as características físicas e químicas do produto final. Como caracterização física das partículas de arroz parboilizado, seco em leito do jorro, foi efetuado, o diâmetro de partícula, esfericidade e massa específica, apresentado valores de 2,27 mm, 0,83 e 1,20 g/ $\mathrm{cm}^{3}$ respectivamente. As condições para os parâmetros carga de alimentação e temperatura definidas na secagem do arroz parboilizado foram de $1000 \mathrm{~g}$ e temperatura de $40^{\circ} \mathrm{C}$ e $60^{\circ} \mathrm{C}$ em um tempo de 45 minutos. Como resultado para as amostras $1 \mathrm{~B}$ e $2 \mathrm{~B}$, foi possível obter os seguintes valores de umidade de $15,7 \%$ e $15,1 \%$, rendimento de $76,56 \%$ e $75,37 \%$, atividade de água de 0,678 e 0,670 respectivamente. As amostras 1B e 2B apresentaram coloração mais escura que amostra controle de arroz branco, conforme sistema de análise de cor CIELAB.

Palavras-chave: Arroz parboilizado, secagem de arroz, leito de jorro.

\begin{abstract}
Rice is one of the main energy supply products of a contemporary society, and it is therefore essential to study processes that come from the perspective of obtaining a product with functional and organoleptic properties suitable for human consumption. The objective of the present work was to analyze the effects of the temperature and feed load variables of the stream bed in the drying process of the parboiled rice, evaluating the physical and chemical characteristics of the parboiled rice. The particle diameter, sphericity and specific mass of the parboiled rice particles were determined by the parboiled rice particles, with values of $2.27 \mathrm{~mm}, 0.83$ and $1.20 \mathrm{~g} / \mathrm{cm}^{3}$, respectively. The
\end{abstract}


conditions for the feedstock and temperature parameters defined in the drying of the parboiled rice were $1000 \mathrm{~g}$ and temperature of $40^{\circ} \mathrm{C}$ and $60^{\circ} \mathrm{C}$ in a time of 45 minutes. As a result for samples $1 \mathrm{~B}$ and $2 \mathrm{~B}$, it was possible to obtain the following moisture values of $15.7 \%$ and $15.1 \%$, yield of $76.56 \%$ and $75.37 \%$, water activity of 0,678 and 0,670 respectively. Samples $1 \mathrm{~B}$ and $2 \mathrm{~B}$ showed darker staining than control sample of white rice, according to CIELAB color analysis system.

Keywords: Parboiled rice, rice drying, spout bed.

\section{RESUMEN}

El arroz es uno de los principales productos de suministro energético de una sociedad contemporánea, por lo que resulta indispensable estudiar procesos que vengan en la perspectiva de obtener un producto con propiedades funcionales y organolépticas adecuadas al consumo humano. El presente trabajo tuvo como objetivo analizar los efectos de las variables temperatura y carga de alimentación del secador lecho de chorro en el proceso de secado del arroz parboilizado, evaluando las características físicas y químicas del arroz parboilizado. Como caracterización física de las partículas de arroz parboilizado, seco en lecho del chorro, fue efectuado, el diámetro de partícula, esfericidad y masa específica, presentado valores de $2,27 \mathrm{~mm}, 0,83$ y $1,20 \mathrm{~g} / \mathrm{cm}^{3}$ respectivamente. Las condiciones para los parámetros carga de alimentación y temperatura definidas en el secado del arroz parboilizado fueron de 1000 g y temperatura de $40^{\circ} \mathrm{C}$ y $60^{\circ} \mathrm{C}$ en un tiempo de 45 minutos. Como resultado para las muestras $1 \mathrm{~B}$ y $2 \mathrm{~B}$, fue posible obtener los siguientes valores de humedad del $15,7 \%$ y $15,1 \%$, rendimiento del 76,56\% y del 75,37\%, actividad de agua de 0,678 y 0,670 respectivamente. Las muestras 1B y 2B presentaron coloración más oscura que muestra control de arroz blanco, según el sistema de análisis de color CIELAB.

Descriptores: Arroz parboilizado, secado de arroz, lecho de chorro.

\section{INTRODUÇÃO}

$\mathrm{O}$ arroz é um alimento complexo e primordial para a contínua estabilidade do balanceamento energético de uma grande parte da população mundial, apresentando segundo a FOA (Food and Agriculture Organization of the United Nations) um crescimento exponencial de $0,9 \%$ ao ano no mercado mundial, principalmente integrando a subcultura em uma alimentação saudável da sociedade brasileira (FOA ONLINE, 2017), tornando-se assim, um dos principais produtos de consumo de uma sociedade moderna, apresentado características e aspectos constituídas basicamente por uma percentagem significativa de valor energético, carboidratos, proteínas, vitaminas de complexo B, gorduras saturadas e fibras alimentar (WALTER, 2007).
A qualidade sensorial, bioquímica e físicoquímica se tornam aspectos fundamentais para a aceitação do consumo do grão no mercado, exigindo assim padrões de qualidade bastante eficientes que visão especificamente, a cor, o sabor, textura e que apresente intuitivamente a ausência de qualquer contaminação, microbiológica, física e/ou química. Os efeitos de qualidade são fatores compostos por um conjunto de ações, aplicadas e absorvidas durante todo o processamento do grão, levando em consideração as características de cultivo, manejo, armazenamento, processo de transformação e conservação (FERREIRA, 2005).

Neste aspecto, a parboilização de arroz é um requisito qualitativo importante na agregação do conjunto de valores nutricionais, com a finalidade de reduzir o número de grãos quebrados e viabilizar a 
transferência quantitativa de vitaminas e sais minerais para o endosperma do grão. $\mathrm{O}$ arroz parboilizado, passa respectivamente por um processo hidrotérmico, caracterizado por etapa de encharcamento aumentando significativamente a percentagem de 30 a $33 \%$ de umidade do grão iniciando o processo de gelatinização e passando por processo de secagem, com a principal fundamentação de garantir a redução significativa de umidade no grão e complementar o processo de gelatinização do amido (PAGÉ, 2016).

A etapa de secagem é um dos pontos cruciais do processo de parboilização do arroz, como um fator relevante para o desenvolvimento e estudo específico das influências e características de processo e conservação, pois a umidade absoluta presente no grão de arroz torna-se um fator intrínseco com grande relevância para qualidade final do produto, em aspecto de desenvolvimento de microrganismos e fungos causadores de deterioração. A efetivação da secagem se torna possível através de inúmeras técnicas, sendo uma delas a técnica de secagem leito de jorro, a qual apresenta um grande potencial para a secagem de cereais, apresentando uma eficiência de alto nível e precisão operacional (USTRA, 2005).

O processo de secagem ou técnica leito de jorro confere a partícula em suspensão uma transferência instantânea e simultânea de calor e massa, possibilitando o controle efetivo da quantidade relativa de umidade. As partículas inerentes caracterizadas por sua densidade absoluta e esfericidade geométrica, apresentam uma personalidade fluidodinâmica específica, como a variação da própria velocidade mínima do leito, em função da perda de carga do ar (MARRETO, 2006).

\section{MATERIAIS E MÉTODOS}

O estudo em questão foi realizado no laboratório de termofluidodinâmica, da engenharia de alimentos da
Universidade Federal de Goiás, os materiais utilizados para os métodos Físico-Químicos foram:

- Matéria prima: arroz agulhinha cultivado em terra alta com casca obtido na escola de agronomia da UFG;

- Termômetros graduados;

- Soprador radial;

- Trocador de calor elétrico;

- Placa de orifício de 2 polegadas;

- Tubulação de aço inox 2 e 5 polegadas;

- Equipamento leito de jorro;

- Cronômetros;

- Recipientes para a coleta de amostras;

- Balança Analítica;

- Autoclave;

- Encharcador;

- Picnômetro;

- Bequer;

- Água Destilada;

- Pisseta;

- Hexano;

- Pentano;

- Álcool;

- Paquímetro;

- Câmara Fria;

- Colorímetro Colorquest XE, Hunterlab ®;

- Aqua Lab cx-2;

- Moinho de martelo;

- Mini Engenho M-T 803-5.

\section{Massa específica do grão de arroz}

A massa específica do arroz foi obtida pelo método de picnometria, consistindo na obtenção de operação aritmética de divisão entre massa e o volume de uma das substâncias, calculando-se o valor da massa específica através da seguinte equação (01):

$$
\begin{aligned}
M_{P}=M g r a ̃ o & +\left(\left(M p i_{c o m} a ́ g u a\right)\right. \\
& \left.-\left(M p i_{c o m} G r a ̃ o\right)\right)(01)
\end{aligned}
$$


Onde,

$\mathrm{Mp}=$ Massa do picnômetro

Mgrão= Massa do grão

Mpi_com_Grão= Massa do picnômetro com grão

Mpi_com_água= Massa do picnômetro com água

Mpi_com_água_Grão= Massa do picnômetro com água e grão

Sendo assim, o cálculo da massa específica do grão, foi efetuado com o auxílio da equação (02).

$$
\rho_{d o} g r a ̃ o=\frac{M G r a ̃ o}{M p} x \rho_{d a} \text { água(02) }
$$

Dado a densidade $(\rho)$ da água a $25^{\circ} \mathrm{C}$ igual a 0,997044 $\mathrm{g} / \mathrm{cm}^{3}$.

\section{Caracterização da partícula de arroz}

Para a execução e análise de caracterização física das partículas de arroz, foi efetuada a realização do método de esfericidade, onde a área de partícula é projetada sobre a área de uma elipse, proposta por (Peçanha e Massarani em 1989) apud Cortez et al. (2008), na qual o volume projetado pode ser calculado com base na equação (03) abaixo.

$$
Y=\frac{V_{e}}{V_{p}}(03)
$$

Onde, $\mathrm{V}_{\mathrm{e}}$ é representado por volume da elipse projetada considerando $\mathrm{Ve}=(4 \Pi a . b . c) / 3$ e $\mathrm{Vp}$ associado ao volume projetado da partícula (arroz), sendo assim, $\mathrm{V} p=\left(4 \Pi r^{3}\right) / 3$. Desta forma, a esfericidade do volume projetado é tomado como parâmetro da radiciação do raio da partícula, calculando assim, a esfericidade obtida a partir da área da partícula projetada representada pela equação (04) abaixo (PEÇANHA, 1986).

$$
\varphi=\frac{A_{e}}{A_{p}}(04)
$$

$\log \mathrm{o}, \mathrm{Ae}=\Pi \mathrm{r}^{3}$ e $\mathrm{Ap}=4 \Pi \mathrm{r}^{2}$

A esfericidade apresentada deve ser menor ou igual há um raio de uma elipse, que apresenta uma esfericidade igual a um. $\mathrm{O}$ diâmetro equivalente da partícula de arroz foi medido com o auxílio de um paquímetro eletrônico, obtendo-se assim, dez amostras relativas de diâmetro equivalente, no qual se considera a média relativa equivalente

A figura 1 abaixo apresenta a dimensão real do raio relativo.

Figura 1. Dimensão elipsoide.

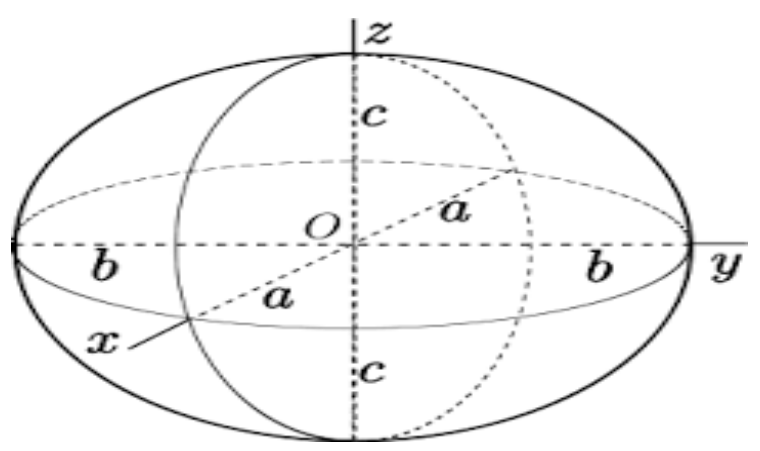

Onde, $(\mathrm{a}=4,83 \mathrm{~mm}),(\mathrm{b}=1,13 \mathrm{~mm}),(\mathrm{c}=1,13 \mathrm{~mm})$.

Fonte: adaptada por Oliveira, 2009.

\section{Parboilização do arroz}

O processo de parboilização seguiu as etapas de encharcamento e autoclavação. No processo de encharcamento foi utilizada uma amostra de $500 \mathrm{~g}$ de arroz com casca, colocada em banho-maria a $65^{\circ} \mathrm{C}$ por 4 horas, em um encharcador com $5000 \mathrm{~W}$ de potência, conforme apresentado na figura 2. Após esta etapa, a água foi drenada do encharcador com o auxílio de uma válvula localizada na parte inferior do equipamento. $\mathrm{O}$ arroz com casca encharcado foi submetido à autoclavagem em pressão manométrica de $1 \times 10^{5} \mathrm{~Pa}$ $\left(121^{\circ} \mathrm{C}\right)$ com tempo de processamento de 10 minutos. 
Figura 2. Encharcado.

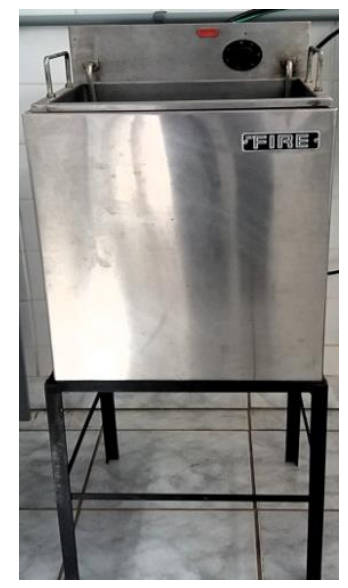

Fonte: autor (2018).

\section{Análise de Umidade}

Para a efetivação da análise de umidade pesouse $5 \mathrm{~g}$ da amostra de arroz parboilizado seco em leito de jorro, em cadinho de porcelana previamente tarado, em balança analítica. Foram anotados os pesos das amostras após a secagem, realizando-se a análise de umidade em triplicata para as amostras secas em leitos de jorro com parâmetro de secagem de $40^{\circ} \mathrm{C}$ e $60^{\circ} \mathrm{C}$. Posteriormente as amostras preparadas em triplicata foram transferidas para estufa de secagem, mantida a $105 \pm 3^{\circ} \mathrm{C}$ por $24 \mathrm{~h}$, segundo o método AOAC $925.45 \mathrm{~b}$ (1997). Após este período os recipientes contendo as amostras secas de arroz parboilizado, foram retiradas da estufa deixadas em repouso em dessecador, onde permaneceram por aproximados 30 minutos, até que o recipiente entrasse em equilíbrio com a temperatura ambiente, o procedimento foi seguido de pesagem das amostras, retornado os cadinhos para a estufa $105 \pm 3^{\circ} \mathrm{C}$ por mais $1 \mathrm{~h}$, repetindo assim a operação até atingir o peso constante das amostras. Para o cálculo de percentagem de umidade foi utilizada a equação 05 estabelecida pelo Ministério da Agricultura (BRASIL, 2009).

$$
\% B s=\frac{(p t f-p z)}{(p z-p f)} x 100(05)
$$

Onde, pf é peso do frasco, ptf o peso do frasco com arroz e pz o peso da amostra da estufa.

\section{Análise de Cor}

$\mathrm{Na}$ análise dos parâmetros de cor dos grãos parboilizados, foi primeiramente utilizado arroz branco, industrializado, como amostra controle da análise. $\mathrm{O}$ procedimento foi efetuado em um colorímetro Colorquest XE, Hunterlab ®. O primeiro passo foi a calibração do instrumento, efetuado com uma placa de padrão preto (zero absoluto) e outra com uma placa de padrão branco. Foram considerados o iluminante D 0,65 com leituras realizadas em triplicatas para cada amostra. As medidas de cor $\mathrm{L}^{*}, \mathrm{a}^{*} \mathrm{e} \mathrm{b}^{*}$ foram determinadas segundo o espaço de cor CIELab, onde a coordenada $L^{*}$ é uma indicação de luminosidade do preto (0) ao branco (100), a coordenada a* é uma indicação de tonalidade na direção do verde para o vermelho e a coordenada $b^{*}$ é uma identificação de tonalidade na direção do azul para o amarelo (GOOD, 2002).

Figura 3. Colorímetro Colorquest XE, Hunterlab ${ }^{\circledR}$.

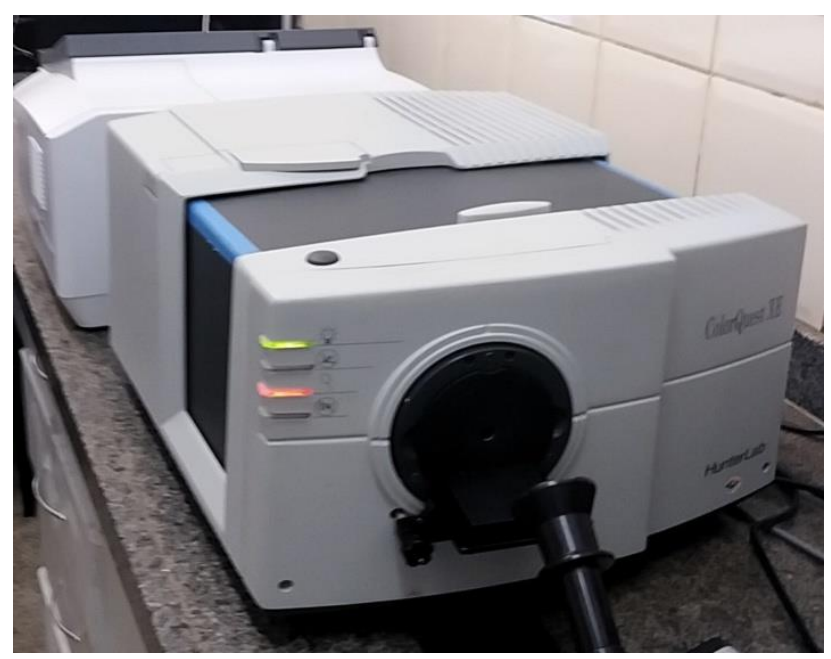

Fonte: autor (2018).

\section{Atividade de água}

Para a análise de atividade de água, as amostras 1B e 2B do arroz parboilizado seco em leito de jorro foram primeiramente separadas em triplicata. Sendo 
então, posteriormente trituras em moinho de martelo, no laboratório de termofluidodinâmica da engenharia de alimentos da Universidade Federal de Goiás. Em seguida as amostras foram disponibilizadas em cubetas e inseridas no Aqua Lab cx-2, para medir a quantidade de água livre presente nas amostras, esperando assim, o tempo de equilíbrio de vapor e ajustando a temperatura de calibração à $25^{\circ} \mathrm{C}$.

\section{Beneficiamento do arroz parboilizado e cálculo do rendimento de grãos inteiros}

O rendimento de grãos inteiros foi determinado em triplicata, segundo a legislação vigente, (BRASIL, 1988). Após a secagem dos grãos de arroz, em leito de jorro, foi coletada $100 \mathrm{~g}$ de mostra de arroz seco em casca e levou-se então para o processo de descascamento em Mini Engenho, conforme figura 4, obtendo-se, então, amostras de arroz descascadas e polidas. A amostra obtida foi pesada para a determinação da porcentagem de grãos polidos (inteiros, quebrados, casca e farelo). Em seguida, os grãos inteiros foram selecionados, por meio do trieur $\mathrm{n}^{\circ} 2$, e pesados. A porcentagem de rendimento foi calculada pela equação 06.

$$
R=\frac{\text { Grãointeiros }}{\text { Pesodoarrozemcasca }} \times 100(06)
$$

Figura 4. Mine Engenho

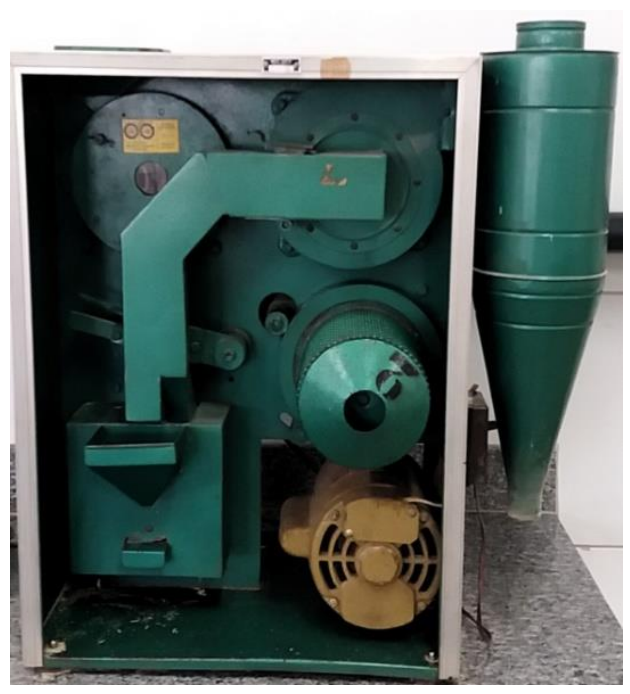

Fonte: autor (2018)

\section{Dimensionamento do leito de jorro}

O secador leito de jorro foi construído em aço inox a partir das seguintes dimensões; altura total da célula de secagem de $700 \mathrm{~mm}$ com ângulo da parte cônica de 60 graus, o diâmetro de entrada do cone (parte inferior) de $30,5 \mathrm{~mm}$, diâmetro do cilindro de $210 \mathrm{~mm}$, um ciclone lapple de aço inox com diâmetro de $100 \mathrm{~mm}$ e comprimento de $200 \mathrm{~mm}$, trocador de calor elétrico cilíndrico de 5 polegadas, de $2000 \mathrm{~W}$ de potência, composto por duas resistências de 1000 W cada uma, conectadas a um controlador de temperatura digital, 4,9 metros de tubulação de 2 polegadas de aço inox, duas válvulas de esfera, de duas polegadas, conexões, e um soprador radial de 7,5 cv.

O diagrama esquemático de montagem do equipamento de leito de jorro pode ser observado conforme a figura 05 .

Figura 5. Diagrama esquemático do secador leito de jorro.

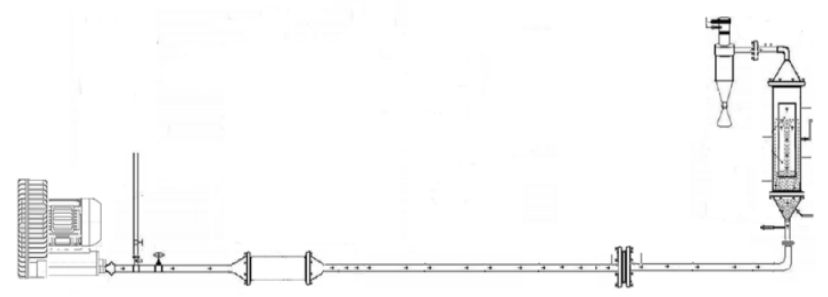

Fonte: autor (2018).

\section{RESULTADOS E DISCUSSÃO}

Os resultados da caracterização física das partículas de arroz são apresentados na tabela 1. Pode ser observado na tabela 1 , que as partículas de arroz apresentaram valor de esfericidade de 0,83 o que já era esperado pelo fato da partícula de arroz apresentar geometria fusiforme, elipsoide longo. 
Tabela 1. Resultados obtido através da caracterização de física de partícula.

\begin{tabular}{lccccc}
\hline Amostra & $\begin{array}{c}\mathrm{D} \\
\text { maior } \\
(\mathrm{mm})\end{array}$ & $\begin{array}{c}\text { menor } \\
(\mathrm{mm})\end{array}$ & $Y$ & $\varphi$ & $\begin{array}{c}\rho \\
\left(\mathrm{g} / \mathrm{cm}^{3}\right)\end{array}$ \\
\hline Arroz & 9,66 & 2,27 & 4,27 & 0,83 & 1,20 \\
\hline
\end{tabular}

Y: Volume projetado da esfera, $\varphi$ : Esfericidade

Os valores para esfericidade encontrado no presente trabalho para a variedade de arroz em casca, da variedade Agulhinha Serra Dourada foram superiores a valores encontrados na literatura por (USTRA, 2005), o qual para o arroz em casca IRGA 418 obteve um valor médio de esfericidade de 0,37.

$\mathrm{O}$ valor encontrado para massa específica do arroz agulhinha a uma temperatura de $25^{\circ} \mathrm{C}$ foi de 1,20 $\mathrm{g} / \mathrm{cm}^{3}$, segundo Grazioli et al. (2010), através do método de caracterização física de diferentes partículas sólidas, obtiveram resultados de massa específica do arroz na ordem de $1,17 \mathrm{~g} / \mathrm{cm}^{3}$, ficando muito próximo do valor encontrado na tabela 1 , e para a esfericidade na literatura o valor apresentado é de 0,74 visto que para o presente trabalho em estudo o valor de esfericidade calculado através da equação (04) é de 0,83 apresentando assim, uma partícula de arroz mais próxima geometricamente de uma elipse do que o valor encontrando de esfericidade na literatura. Para Foltin et al. (2013), o resultado da caracterização fusiforme das partículas de arroz, determinam um comportamento fluidodinâmico característico na secagem em leito de jorro, quanto maior o valor de esfericidade menor será a porosidade do leito particulado, pois quanto maior a porosidade menor a perda de carga do sistema, uma vez que, se a porosidade sofrer pequenas alterações, devido ao empacotamento particular do leito, a queda de pressão é afetada.

A tabela 2 apresenta resultados para os valores de rendimento das amostras de arroz parboilizado secas em leito de jorro, com parâmetros de secagem de menor temperatura, de $40^{\circ} \mathrm{C}$ e maior temperatura, de $60^{\circ} \mathrm{C}$, utilizando o tempo de 45 minutos.

Tabela 2. Rendimento do arroz parboilizado.

\begin{tabular}{lccccc}
\hline Amostra & $\begin{array}{c}\text { Carga } \\
(\mathrm{g})\end{array}$ & $\begin{array}{c}\mathrm{t} \\
\text { SEC } \\
(\mathrm{min})\end{array}$ & $\begin{array}{c}\mathrm{T} \\
\text { SEC } \\
\left({ }^{\circ} \mathrm{C}\right)\end{array}$ & $\mathbf{U}(\%)$ & $\mathbf{R}(\%)$ \\
\hline $\begin{array}{l}\text { Arroz } \\
\text { Parboiliz- } \\
\text { ado 1B }\end{array}$ & $1.000,00$ & 45,00 & 40,00 & 15,70 & 76,56 \\
\hline $\begin{array}{l}\text { Arroz } \\
\begin{array}{l}\text { Parboiliz- } \\
\text { ado 2B }\end{array}\end{array}$ & $1.000,00$ & 45,00 & 60,00 & 15,10 & 75,37 \\
\hline
\end{tabular}

T: temperatura de secagem em graus Celsius; t: tempo de secagem em minutos; U: umidade; R: rendimento.

De acordo com os dados obtidos na etapa de secagem do arroz parboilizado, observou-se uma pequena diferença percentual no rendimento final das amostras tratadas, conforme as diferentes temperaturas de operação aplicadas no processo de secagem. A amostra 1B apresentou um rendimento levemente maior que amostra do 2B. A quantidade de umidade presente na amostra torna-se um fator no qual irá interferi diretamente no número de grãos inteiros na etapa de descascamento do arroz, sendo possível observar que quanto maior o valor de umidade presente no grão de arroz após a secagem, maior será respectivamente o rendimento do produto final, diminuindo assim o número de quebrados no descascamento, pois a amostra com menor efeito de desidratação térmica ou retrogradação no processo de secagem, faz com que as partículas de grânulos gelatinizado no processo de encharcamento sofram menos com baixa resistência a quebra no rendimento final (FONSECA, 2009).

A tabela 3 apresenta os resultados da análise de atividade de água para as amostras de arroz parboilizado $1 \mathrm{~B}$ e $2 \mathrm{~B}$, secas com temperatura de $40^{\circ} \mathrm{C}$ e $60^{\circ} \mathrm{C}$ respectivamente. 
Tabela 3. Atividade de Água (aw)

\begin{tabular}{lcccc}
\hline \multicolumn{1}{c}{ Amostra } & $\begin{array}{c}\text { Atividade } \\
\text { de água } \\
\text { (aw) }\end{array}$ & $\mathrm{S}^{2}$ & $\mathbf{T}\left({ }^{\circ} \mathbf{C}\right)$ & $\mathbf{S}^{2}$ \\
\hline $\begin{array}{l}\text { Arroz } \\
\text { Controle }\end{array}$ & 0,508 & 0,00636 & 25,83 & 1,63 \\
\hline $\begin{array}{l}\text { Arroz } \\
\text { Parboilizado } \\
\text { 1B }\end{array}$ & 0,678 & 0,00264 & 26,06 & 0,12 \\
\hline $\begin{array}{l}\text { Arroz } \\
\text { Parboilizado } \\
\text { 2B }\end{array}$ & 0,670 & 0,00469 & 26,30 & 0,10 \\
\hline
\end{tabular}

Com base na análise estatística dos resultados observados, para as condições de operação nas quais as amostras 1B e 2B foram obtidas, a atividade de água apresentada pelas amostras ficou na faixa de $0,678 \mathrm{e}$ 0,670 com desvio padrão de 0,00264 e 0,00469 respectivamente. Os valores apresentados podem ser promissores considerando o binômino tempo $\mathrm{e}$ temperatura aplicados no processo de secagem das amostras em estudo. Na literatura os valores encontrados para a umidade e atividade de água com parâmetro de secagem tempo e temperatura definidos, foram semelhante ao presente trabalho, pois como esperado conforme o aumento da taxa de temperatura, menor é a quantidade de atividade de água e umidade na amostra.

Entretanto, segundo a legislação padrão, a qual determinar a quantidade parcial de atividade de água presente no grão de arroz e umidade (Ministério Agricultura Pecuária e abastecimento), para as condições ideais de armazenamento, é estipulado um valor de umidade aproximadamente de $13 \%$ e uma atividade de água inferior a 0,60, para evitar o crescimento indesejável de fungos e levedura, pois em condições de atividade de água (aw) superiores a 0,60, conforme são apresentados na tabela 4, algumas bactérias halófitas, leveduras e fungos xerofílicos podem se desenvolver segundo Gock et al. (2003). Para uma melhor apresentação dos resultados de secagem, com atividades de água segundo o padrão estipulado pela legislação é necessário alterar os parâmetros tempo e temperatura de secagem.
Tabela 4. Valores mínimo de atividade de água (aw) para o crescimento e produção de patógenos

\begin{tabular}{lcc}
\hline Microrganismo & $\begin{array}{c}\text { (aw) para } \\
\text { crescimento }\end{array}$ & $\begin{array}{c}\text { Aw para } \\
\text { produção de } \\
\text { toxina }\end{array}$ \\
\hline A. flavus & $0,78-0,80$ & $\begin{array}{c}0,83-0,87 \\
\text { (aflatoxina) }\end{array}$ \\
\hline A. ochraceus & $0,77-0,83$ & $\begin{array}{c}0,83-0,87 \\
\text { (ocratoxina A) }\end{array}$ \\
\hline
\end{tabular}

\begin{tabular}{ll}
\hline $\begin{array}{l}\text { Bactérias } \\
\text { halofilicas }\end{array}$ & 0,75 \\
\hline
\end{tabular}

\begin{tabular}{ll}
\hline $\begin{array}{l}\text { Bolores } \\
\text { xerofilicas }\end{array}$ & 0,65 \\
\hline
\end{tabular}

Fungos
osmofílicos $\quad 0,60$

Fonte: adaptado por Beauchat, 1981.

Com os valores de umidade presente no grão de arroz a partir da operação de secagem, foi obtido como parâmetro na tabela 5 os resultados para análise de cor expresso por meio das escalas $L^{*}, a^{*} e$ b* em relação à umidade final presente nas amostras $1 \mathrm{~B}$ e $2 \mathrm{~B}$ de arroz parboilizado, com teores de umidade $15,7 \%$ e $15,1 \%$.

Tabela 5. Teores de umidade sobre a cor do arroz parboilizado

\begin{tabular}{lccc}
\multicolumn{1}{c}{ Tratamento } & $\mathrm{L}^{*}$ & $\mathrm{a}^{*}$ & $\mathbf{b}^{*}$ \\
\hline & Amostra controle $(\mathrm{C})$ \\
\hline BRS & 58,2 & $-0,92$ & 7,34 \\
\hline Agulhinha & \multicolumn{3}{c}{ Teores de umidade (U) } \\
\hline $\mathbf{1 5 , 7 \%}$ 1B & 46,37 & 2,50 & 26,06 \\
\hline $\mathbf{1 5 , 1 \%} \mathbf{2 B}$ & 44,66 & 2,97 & 14,98 \\
\hline
\end{tabular}

L*: Luminosidade $(0=$ escuro $),(100=$ claro $)$;

Coordenada de Cromaticidade: $\mathrm{a}^{*}$ : (-) verde vermelho (+) b*: (-) azul amarelo (+).

A escala $L^{*}$ na tabela 5 representa o quanto a amostra analisada apresenta uma tonalidade mais clara segundo (GOOD, 2002). O resultado explicito na tabela 5 mostra que o parâmetro $L^{*}$ da amostra $1 \mathrm{~B}$ é maior que o resultado da escala $L^{*}$ da amostra $2 B$, ou seja, a amostra $1 \mathrm{~B}$ apresenta uma tonalidade mais clara que a amostra 2B, e a amostra de controle apresentou 
uma escala $\mathrm{L}^{*}$ superior a amostra $1 \mathrm{~B}$ e $2 \mathrm{~B}$, o que já era esperado. Para este resultado é possível analisar que a amostra submetida a parboilização tem influência na escala $\mathrm{L}^{*}$ de tonalidade, os valores crescente da $\mathrm{L}^{*}$ podem ser explicados em relação à variação do tempo em que o grão de arroz é submetido ao encharcamento, pois quanto maior a temperatura de encharcamento menor será a claridade da amostra, segundo Garcia et al. (2009), o parâmetro tempo de encharcamento é um fator de escurecimento da amostra, a possível causa está na perda de compostos que estão presente no grão de arroz para água do processo durante o encharcamento, as enzimas presentes tanto nas camadas externas quanto no endosperma do arroz, são ativadas, favorecendo a hidrólise do amido com a produção de açúcares redutores, como a glucose. Após o processo de submissão das amostras $1 \mathrm{~B}$ e $2 \mathrm{~B}$ no encharcamento foi possível observar que a água utilizada apresentou uma cor amarelada (BOBBIO, 2001).

A figura 6 apresenta uma diferença perceptível na coloração das partículas de arroz em seu diferente estado de operação.

Figura 6. Arroz branco e Arroz parboilizado.

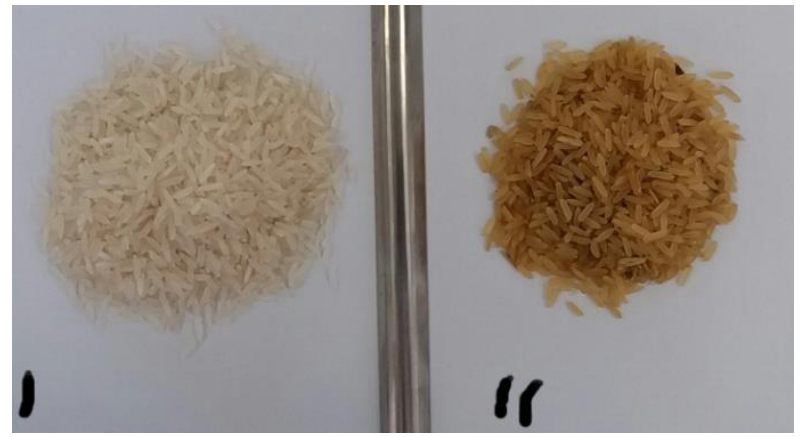

I) Arroz branca agulhinha 13,5\% umidade e II) Arroz parboilizado amostra 1B 15,7\% umidade.

A figura 7 representa a diferença de tonalidade entre o arroz parboilizado $2 \mathrm{~B}$ e amostra de controle arroz branco.
Figura 7. Arroz branco e Arroz parboilizado.

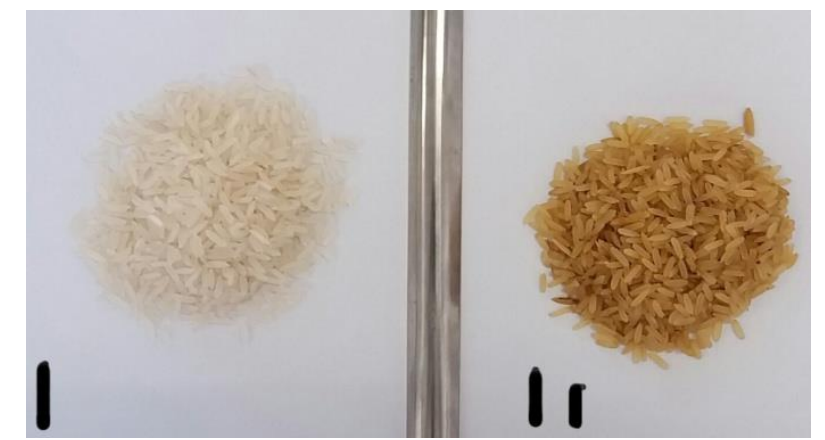

I) Arroz branca agulhinha 13,5\% umidade e II) Arroz parboilizado amostra 2B 15,1\% umidade.

A escala $\mathrm{a}^{*}$ representa a tonalidade que varia relativamente entre a cor verde e vermelho (GOOD, 2002). A amostra 1B apresentou uma a escala $a^{*}$ de 2,50 menor que escala $a^{*} 2,97$ da amostra $2 B$. A amostra 1B e 2B estão significantemente mais próximas da cor vermelha, pois o resultado apresentado neste trabalho, é semelhante ao discutido por Caliari (2011); Fonseca et al. (2009), ao submeter as amostras de arroz em tempos de encharcamento aproximadamente de $240 \mathrm{~min}$ e $500 \mathrm{~min}$ e temperaturas de encharcamento de $62^{\circ} \mathrm{C}$ e $66^{\circ} \mathrm{C}$, estas podem apresentar a capacidade de dissolver certas substâncias presentes no grão, proporcionando a elevação da escala $a^{*}$, ou seja, quanto maior a variação do tempo de submissão das partículas de arroz no encharcamento, ou quanto maior a temperatura de encharcamento aplicada no processo, maiores serão os valores da escala $a^{*}$.

Para a escala $b^{*}$ é representado a tonalidade relacionada entre a cor azul e amarelo (GOOD, 2002). Os resultados da tabela 5 mostram que o valor da amostra $1 \mathrm{~B}$ é maior que a $2 \mathrm{~B}$, sendo assim o tratamento 1B apresenta uma cor amarela mais escura, demostrado na figura 6 e o tratamento $2 \mathrm{~B}$ uma cor amarelo mais claro, apresentado na figura 7. As amostras apresentaram uma escala $b^{*}$ na faixa 14,09 a 26,6, Segundo Silveira Filho (2002); Garcia et al. (2009), os resultados encontrados para a escala $b^{*}$ de arroz parboilizado encontram-se próximos de 20,6, pois 
neste processo criam-se condições para a reação de escurecimento não enzimática do tipo Maillard, ocorrendo uma tendência à acentuação da coloração típica do arroz parboilizado.

\section{CONCLUSÃO}

A técnica de secagem em leito de jorro se mostrou promissora para a secagem de grãos de arroz parboilizado. Os resultados obtidos a partir dos experimentos de secagem foram satisfatórios em relação ao binômio taxa de umidade e número de partículas de arroz inteiro, segundo os valores encontrados na literatura, mantendo assim a qualidade do produto final, apresentando, portanto, um teor de quebrados abaixo de (25\%). O produto final seco em leito de jorro apresentou, ainda, valores de umidade na faixa de $15,7 \%$ e $15,1 \%$, e atividade de água na faixa de $(0,678$ e 0,670$)$, respectivamente, paras as amostras $1 \mathrm{~B}$ e $2 \mathrm{~B}$, sendo diretamente influenciadas pelas variáveis tempo de secagem (45 minutos), temperaturas de secagem $\left(40^{\circ} \mathrm{C}\right.$ e $\left.60^{\circ} \mathrm{C}\right)$ e carga de alimentação (1000 g), o que favoreceu um maior rendimento na etapa de descascamento do arroz, com teor de inteiros na faixa de $75 \%$. Como esperado as partículas de arroz agulhinha ficaram enquadradas geometricamente fusiforme com esfericidade de 0,83 próximo de valores encontrados na literatura. $\mathrm{O}$ arroz parboilizado apresentou ainda coloração amarelada, condizente com o esperado, cor que pode ter sido influenciada pelas reações de escurecimento de Maillard.

\section{AGRADECIMENTO}

Agradecemos todos os colaborados desta pesquisa, que diretamente e indiretamente contribuíram no desenvolvimento, elaboração, dedicação e empenho do projeto como um todo. Agradecemos ao Professor e coordenador da pesquisa Dr. Gilberto Goulart na supervisão geral de um grupo de pesquisa ou suporte administrativo geral, e apoio na edição técnica, revisão idiomática e revisão final.

Agradecemos também a Universidade Federal de Goiás por proporcionar a capacitação e criação na inovação tecnológica científica. Agradecemos por fim, todos os colaboradores que disponibilizaram as matérias primas e recurso para a conclusão da pesquisa.

Todos os autores declararam não haver nenhum potencial conflito de interesses referente a este artigo.

\section{REFERÊNCIAS}

BRASIL, Ministério da Agricultura e Reforma Agrária. Regras para análise de sementes. Brasília; 2009.

BRASIL, Ministério da Agricultura, Pecuária e Abastecimento. Norma de identidade, qualidade, embalagem e apresentação do arroz. Brasília, 28p, 1988.

BOBBIO, A., P., FLORINDA, A., F., Química Do

Processamento De Alimentos. 3 ed., São Paulo. 2001.

CASTRO, E.M.; VIEIRA, N.RA.; RABELO, R.R.; SILVA, S.A.; Qualidade do grão de arroz. Embrapa arroz e feijão, 1999.

CESAR, J.; ANDRADADE, J.C.; DE PAOLI, M-A., A determinação da densidade de sólidos e líquidos, Chemkys, p.5-8, 2004.

DONIDA, M.W .; Recobrimento Polimérico da Uréia em Leito de jorro Bidimensional. Dissertação de Mestrado. Faculdade de Engenharia Química, UNICAMP, Campinas-SP; 2000.

FERREIRA, C.M.; PINHEIRO, B. da S.; SOUSA, I.S.F. de; MORAIS, O.P. de. Qualidade do arroz no Brasil: evolução e padronização. Santo Antônio de Goiás: Embrapa Arroz e Feijão, 2005. 
FONSECA, Condições de encharcamento sobre a qualidade do arroz parboilizado cultivado em terras altas. Dissertação de Mestrado. Universidade Federal De Goiás; 2009

FONSECA, F.; SOARES, M.S.; CALIARI, M.; Efeito da temperatura e do tempo de imersão da etapa de encharcamento sobre a cor dos grãos de arroz parboilizado de cultivares de terras altas. Ciências Agrárias, Londrina, v. 32, n. 1, p. 221-234

Foltin, J. P, Avaliação da Perda de Carga em Leito Fixo de Partículas Irregulares Utilizando Xisto Betuminoso, Analisando a Modelagem Matemática Através do Efeito de Parede e Porosidade. Dissertação de mestrado. Universidade Federal do Paraná - UFPR, Curitiba - PR, 104p, 2013.

FOA, ONLINE, 2017. Pesquisa do levantamento técnico do comércio arroz, FOA (Food and Agriculture Organization of the United Nations). Disponível em: http://www.fao.org/economic/est/publications/publica ciones-sobre-el-arroz/seguimiento-del-mercado-delarroz-sma/es/. Acessada em 21/07/2017.

FITZGERALD, M.; LEWIN, L.; WILLIAMS, R.; CLAMPETT, W. S.; REINKE, R. Grain quality. In: KEALEY, L. M.; CLAMPETT, W. S. (Ed.). Production of quality rice in South Eastern Australia. Kingston: Rural Industries Research \& Development Corporation (RIRDC), 2000.

FREIRE, J. T.; OLIVERIRA, W. P., In: FREIRE, J. T., SARTORI, D. J. M. “Tópicos especiais em secagem.” Editora São Carlos, UFSCar, São Carlos, SP, p. 253290. 1992.

GOCK, M. A.; HOCKING, A. D.; Influence of temperature, water actvity and $\mathrm{PH}$ growt of same xerophilic fungi. International Journal of food Microbiology,2003.
GINIANI, C.D; RENATA, H.P; ELIANA, B.F; Influência das condições de parboilização na composição química do arroz, 2009.

GRAZIOLI, A. S., ANDRADE, B.L.B., MAITO E., BARBOSA, F. S., PINHEIRO, M.F., POLI, V.L; Caracterização física de diferentes partículas sólidas, Universidade Federal do Pampa, UNIPAMPA, 2010.

GOOD, H. et al.; Measurement of color in cereal products. Cereal Foods World, Minneapolis,2002.

GOULART, G., A., S., Secagem de plasma bovino em leito de jorro cônico, Dissertação de Mestrado.Fundação Universidade Federal do Rio Grande - RS; 2000.

ISHIKURA, T. et al.: "Hydrodynamics of a spouted bed with a porous draft tube containing a small amount of finer particles"; Powder Technology, 2003.

KUNII, D.; LEVENSPIEL, O.; Fluidization Engineering, $2^{\mathrm{a}}$ edição, Stoneham, ButterworthHeinemann, 1991.

MARRETO, R.N; Estudo Da Técnica De Leito De Jorro Convencional Para Secagem De Microscopia De Caseína E Proteínas. Dissertação de Mestrado. Faculdade de Ciência Farmacêutica, FCFRP-USP, Ribeirão Preto-SP; 2005.

MATHUR, K. B. \& EPSTEIN, N., Spouted Beds., Academic Press Inc, 1974.

MONTEIRO, Dimensionamento de um secador de milho com 60 t/dia de capacidade, Dissertação de Mestrado. Faculdade de Engenharia da Universidade do Porto, FEUP, Porto - Po; 2011.

PAGÉ, sistema de parbolização por vapor (autoclave), julho 2016. Disponível em: http://www.page.ind.br/_pdf/a269a680f5a2a95ee21c8 65ab106a462.pdf. Acessado em 22/07/2017. 
PEÇANHA, R.P.; MASSARANI, G., Dimensão característica e forma de partículas, XIV Encontro Nacional de Escoamento em Meios Porosos, ENEMP, 1986.

SALEH, K. et al.; "Experimental study and modeling of fluidized bed coating and agglomeration"; Powder Technology, 2003.

USTRA, Secagem de grãos de arroz em leito fluidizado. Dissertação de Mestrado. Faculdade deAgronomia Eliseu Maciel, Pelotas - RS, 95p; 2005. VIEIRA, N. R. A.; RABELO, R. R. Qualidade tecnológica. In: SANTOS, A. B.; STONE, L.F.; VIEIRA, N. R. A. (Ed.). A cultura do arroz no Brasil. 2. ed. Santo Antônio de Goiás: Embrapa Arroz e Feijão, 2006.

WALTER, M; MARCHEZAN, E; AVLA, L.A; Arroz composição e características nutricionais. Ciência Rural, Santa Maria, v.38, n.4, p.1184-1192; 2008.

ZACZUK, P.; JOSIANY A.B.; Qualidade do grão. AGEITEC Agência Embrapa de informação tecnologica,2017.

OLIVEIRA, 2009. Superfícies Quádricas figura apresentada na observação geométrica para o calculo de volume de elipse. Disponível em: http://www.ebah.com.br/content/ABAAAAk1IAC/su perficies-quadricas. Acessado em 02/08/2017. 